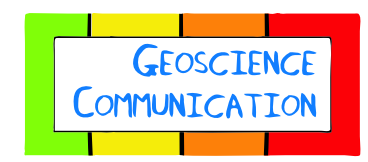

\title{
Introduction: Five years of Earth sciences and art at the EGU General Assembly (2015-2019)
}

\author{
Tiziana Lanza \\ Istituto Nazionale di Geofisica e Vulcanologia (INGV), Rome, Italy
}

Correspondence: Tiziana Lanza (tiziana.lanza@ingv.it)

Published: 15 May 2020

At the 2015 EGU General Assembly a session dedicated to Earth sciences and art was proposed for the first time. However, even then there were already many different initiatives operating in this direction across the globe, several of which had been doing so for many years. Many research institutes, for instance, have long since adopted residencies for artists, giving scientists the opportunity to confront themselves with different cultural domains. Of course, the benefits of such an encounter are mutual, since artists can themselves also receive inspiration from science.

Also in 2015, the Joint Research Centre (JRC) of the European Commission (located in Ispra, Italy) launched for the first time a call for the Resonances Festival, an initiative dedicated to SciArt projects, and which was scheduled to take place every two years. The term SciArt (Science \& Art) refers to all the activities involving collaboration between scientists and artists, and the initial festival was the result of an intense amount of work, co-ordinated by the SciArt project leader Adriaan Eeckels, the curator Freddy Paul Grunert, the head of the Scientific Development Unit at the JRC Jutta Thielen-del Pozo, the geoscientist Francesco Mugnai, and the architect Cristina Fiordimela. After this initial call, and over the course of the next two years, scientists and artists worked in close collaboration, the first step of which was an intense summer school for the artists to acquire the scientific basis for their future installations. In the months that followed, they worked together to inspire one another and to collaboratively create new works of art. Finally, the festival collected all the works in an exhibition at the JRC, and, as a result of this, several of the participants have since collaborated in convening the Earth sciences and art sessions at the EGU General Assembly.

Some of the people mentioned above have been involved in helping to curate this special issue. In addition, we have also had the pleasure to collaborate with Isaac Kerlow, an artist and film-maker, who is a long-time participant of the Earth Sciences \& Art sessions, and who brings with him decennial experience at the Earth Observatory in Singapore in using different forms of art to engage people with the communication of natural hazards. This special issue also includes editorial support from Angela Saraò, a seismologist at the Osservatorio Geofisico Sperimentale in Trieste (Italy); Antonio Menghini, a geoscientist and musician from Viterbo (Italy); and George Sand França, a professor in seismology and performer from the University of Brasilia (Brazil).

These interdisciplinary and international collaborations have been made possible because of the past five years of Earth sciences and art sessions at the EGU General Assembly. Similarly, these sessions have made it possible for people working in the intersections of the geosciences and the arts to encounter and collaborate with one another. In these five years we have had 87 presentations - most of which have involved geosciences coupling with digital and visual arts (14), music and acoustics (18), and theatre and performance (12). Others have involved topics such as science narrative, gamification, photography, geotourism, and cultural heritage.

Beyond the immediate goal of enabling geoscientists and artists to share their experiences of working in the intersections of the two fields, we wanted to contribute towards recovering from the past demarcation of the two cultures, i.e. the humanities and science. The need for a collaborative space in which science and art can work together is imperative today, as some studies on their synergies already show (Kimbal, 1994; Ball and Ede, 2017; Sleigh and Craske, 2017). Furthermore, artists can take inspiration from the work of scientists, who, in turn, can take inspiration from the work of artists. Similarly, artists in their emotional ap- 
proach to reality can contribute towards stimulating the intuitive mind of scientists.

In working together to help solve the wicked problems that are deteriorating both our planet's resources and also our quality of life, the humanities can find a powerful ally in geoscience for re-awakening in everybody the sense of beauty, values, and respect for the planet. We believe that to know Earth is to love Earth, since nature is in itself a work of art; Earth sciences dig out all the secrets that make our planet a unique place in the Universe we know. An aurora, for instance, can inspire poetry for its beauty whilst simultaneously being describable in scientific terms as a result of the interaction between the solar wind and the Earth's magnetic field.

We hope that this special issue will help to inspire those geoscientists who have never before considered collaborating with artists. Secondly, we hope to attract other artists and welcome them into the geosciences. Finally, we hope that the development of a unified culture will help to involve everybody in a deeper knowledge of the Earth and its delicate and complex mechanisms, and that by doing so we are able to preserve our planet for future generations.
Special issue statement. This article is part of the special issue "Five years of Earth sciences and art at the EGU (2015-2019)". It is not associated with a conference.

\section{References}

Ball, F. and Ede, S.: Art and science - work in progress: observations, opportunities, obstacles, Vol. 1 (of 2), Interdiscipl. Sci. Rev., 42, 309-312, https://doi.org/10.1080/03080188.2017. 1381221, 2017.

Kimbal, R.: The Two Cultures Today in The New Criterion, available at: https://newcriterion.com/issues/1994/2/ aoethe-two-culturesa-today (last access: 20 April 2020), 1994.

Sleigh, C. and Craske, S.: Art and science in the UK: a brief history and critical reflection, Interdiscipl. Sci. Rev., 42, 313-330, https://doi.org/10.1080/03080188.2017.1381223, 2017. 